disease: substantia nigra regional selectivity. Brain. 1991; 114:2283-2301.

5. Bisaglia M., Filograna R., Beltramini M., et al. Are dopamin derivatives implicated in the pathogenesis of Parkinson's disease? Ageing Research Reviews. 2014; 13:107-114.

6. Hoàng Thị Dung (2014), Nghiên cứu đặc điểm lâm sàng và định lượng nông độ Dopamin huyết tương ở bệnh nhân Parkinson, Luận văn thạc sỹ Y hoc, Hoc viên Quân Y, Hà Nôi.

7. Nguyến Đức Thuận, Lê Văn Quân, và Nhữ Đinh Sơn (2020). Thay đổi nông đố Dopamin huyết tương trên bệnh nhân Parkinson. Tạp chí Y dược học quân sự, 2, 116-121.
8. Eldrup E., Mogensen P., Jacobsen J., et al. CSF and Plasma Concentrations of Free Norepinephrine, Dopamin, 3,4-dihydroxyphenylacetic Acid (DOPAC), 3,4-dihydroxyphenylalanine (DOPA), and Epinephrine in Parkinson's Disease. Acta Neurol Scand. 1995; 92(2):116-21.

9. Goldstein S., Holmes C., Sharabi $Y$. Cerebrospinal fluid biomarkers of central catecholamine deficiency in Parkinson's disease and other synucleinopathies. Brain, 2012; 135(6): 1900-1913.

10. Functional and Streotactic Neurology Staging of Parkinson's Disease. MGH Neurosugical Service 1999.

\title{
KẾT QUẢ QUẢN LÝ ĐIỀU TRI LAO KHÁNG RIFAMPICIN TẠI THÁI NGUYÊN GIAI ĐOẠN 2016-2020 VÀ MỘT SỐ YẾU TỐ LIÊN QUAN
}

\section{Đào Thị Hương ${ }^{1}$, Hoàng Hà², Trần Thế Hoàng²}

\section{TÓM TẮT}

Mục tiêu: Mô tả kết quả quản lý điều trị lao kháng Rifampicin tai Thái Nguyên giai đoan 20162020 và một số yếu tố liên quan. Phương pháp nghiên cứu: nghiên cứu mô tả cắt ngang trên 92 bệnh nhân lao kháng Rifampicin giai đoạn 2016-2020 tại Bệnh viện Lao và Bệnh phổi Thái Nguyên. Kết quả: Tuổi trung bình của bệnh nhân lao kháng Rifampicin là 40,9 12,3 , tỉ lệ nam $79,3 \%$. Tỉ lệ có tiền sử điêu trị lao $73,9 \%$, lao mói $26,1 \%$ và $H I V(+)$ $19,6 \%$. Tî lệ lao tại phối $97,8 \%$; thể $A F B(+) 72,8 \%$. Tì lệ tuân thủ xét nghiệm trong quá trình theo dõi điều trị $28,3 \%$. Tỉ lệ điều trị khỏi 3,5\%, hoàn thành điêu trị $75,5 \%$, tử vong $10,5 \%$, thất bại $2,3 \%$, bỏ trị $7,0 \%$, chuyên 1,2\%. Có mối liên quan giữa: tình trạng kinh tế hô gia đình nghèo, tiền sứ lao, mắc bênh kèm theo, $\mathrm{HIV}(+), \mathrm{AFB}(+)$, thời gian điều trị 20 tháng, bệnh nhân tai trai giam, không tuân thủ xét nghiêm và găp tác dụng không mong muốn với kết quả điều trị lao kháng Rifampicin khồng thành công $(p<0,05)$. Kết luận: Tỉ lệ điều trị lao kháng Rifampicin thành công tai Thái Nguyên tương đối cao, các yếu tố về đăc điểm bệnh và tiền sử bệnh có liên quan đến kết quả điêu tri không thành công.

Tư khóa: Quản lý điều trị; Lao kháng Rifampicin; Thái Nguyên.

\section{SUMMARY \\ RESULTS OF TREATMENT MANAGEMENT OF RIFAMPICIN-RESISTANT TUBERCULOSIS IN THAI NGUYEN PERIOD 2016-2020 AND SOME RELATED FACTORS}

\footnotetext{
${ }^{1}$ Bệnh viện Lao và Bệnh phổi Thái Nguyên

${ }^{2}$ Trường Đại hoc Y Dược Thái Nguyên

Chịu trách nhiệm chính: Đào Thị Hương

Email: daohuong1408@gmail.com

Ngày nhân bài: 5.3 .2021

Ngày phản biên khoa hoc: 28.4.2021

Ngày duyệt bài: 11.5.2021
}

Objectives: To describe the results of treatment management of rifampicin-resistant tuberculosis in Thai Nguyen period 2016-2020 and some related factors. Research Method: A cross-sectional descriptive study was conducted on 92 rifampicinresistant patients in the period 2016-2020 at Thai Nguyen Tuberculosis and Lung Disease Hospital. Results: The mean age of rifampicin-resistant patients was $40.9 \pm 12.3$, the male proportion was $79.3 \%$. The proportion of TB retreatment was $73.9 \%$, new cases $26.1 \%$ and $\mathrm{HIV}(+) 19.6 \%$. The proportion of lung TB was $97.8 \%$; $\mathrm{AFB}(+) 72.8 \%$. The proportion of testing adherence during treatment follow-up was $28.3 \%$. The proportion of cure $3.5 \%$, treatment completed $75.5 \%$, death $10.5 \%$, failure $2.3 \%$, dropout $7.0 \%$, transferred out $1.2 \%$. There were relationship between: poor household economic status, TB retreatment, comorbidities, $\operatorname{HIV}(+), \operatorname{AFB}(+), 20$ months treatment duration, patients in prison, non-testing adherence and had adverse drug reaction with unsuccessful treatment of rifampicin-resistant $(p<0.05)$. Conclusion: The proportion of RR-TB successful treatment in Thai Nguyen is relatively high, the retreatment and disease characteristics factors are related to unsuccessful treatment.

Keywords: Treatment management; Rifampicinresistance tuberculosis; Thai Nguyen.

\section{I. Đă̆T VẤN ĐỀ}

Lao kháng thuốc là một vấn đề sức khỏe lớn và đe dọa nghiêm trọng đến các nỗ lực kiểm soát và phòng ngừa bệnh lao trên toàn câu. Việt Nam là nước đứng thứ 11 trong 30 quốc gia có gánh nặng bệnh lao đa kháng thuốc cao nhất thế giới với 3266 bệnh nhân lao kháng thuốc thu nhận điều trị năm 2020 [1], [7]. Trong lao kháng thuốc, lao kháng Rifampicin (RR-TB) (thuốc thiết yếu điêuu trị lao) đang diễn biến phức tap [7]. Năm 2020, Việt Nam phát hiện 3503 bệnh nhân RR-TB trong tổng số 213.375 người được thực 
hiện xét nghiệm kỹ thuật sinh học phân tử GeneXpert [1]. Việc quản lý điều trị bệnh nhân RR-TB phức tạp hợn, cần chú ý nhiều hơn và tỉ lệ điều trị thành công RR-TB không cao khoảng 57,0\% [7]. Từ năm 2014, Chương trình chống lao quốc gia (CTCLQG) đã trang bị hệ thống xét nghiệm GeneXpert để chẩn đoán lao và RR-TB cho các tỉnh thành trên toàn quốc trong đó có Thái Nguyên. Việc thực hiện xét nghiệm GeneXpert đã giúp tăng cường chẩn đoán phát hiện và quản lý điêu trị RR-TB tại Thái Nguyên. Câu hỏi là kết quả quản lý điều tri RR-TB tại Thái Nguyên hiện nay ra sao? Yếu tố nào liên quan đến kết quả điều trị? Do đó, chúng tôi tiến hành nghiên cứu nhằm mục tiêu: Mô tả kết quả quản lý điều trị RR-TB tại Thái Nguyên giai đoạn 2016 -2020 và một số yếu tố liên quan.

\section{II. ĐỐI TƯợNG VÀ PHƯƠNG PHÁP NGHIÊN CỨU}

2.1. Đối tượng nghiên cứu: 92 bệnh nhân RR-TB được quản lý điêu trị tại Thái Nguyên giai đoạn 2016 - 2020.

2.2. Địa điểm, thời gian nghiên cứu: Từ 5/2020-4/2021 tại Bệnh viện Lao và Bệnh phổi Thái Nguyên

\subsection{Phương pháp nghiên cứu:}

- Thiết kế nghiên cứu: Nghiên cứu mô tả cắt ngang.

- Cõ̃ mẫu: toàn bộ. Chọn mẫu: chủ đích.

\subsection{Biến số nghiên cứu:}

Đặc điểm chung: Tuổi, giới, nghề nghiệp, kinh tế hộ gia đình, nơi cư trú.

Quản lý điều trị: Tiền sử lao, bệnh kèm theo, tình trạng HIV, phương pháp chẩn đoán, vị trí tổn thương, thể lao, thời gian chờ điều trị, chế độ điều trị, nơi quản lý ở giai đoạn duy trì, tư vấn trước điều trị, đo thính lực, soi đáy mắt, xét nghiệm công thức máu, xét nghiệm chức năng gan, tuân thủ $\mathrm{XN}$, tác dụng không mong muốn khi dùng thuốc điều trị, kết quả điều trị lao.

2.5. Tiêu chuẩn đánh giá biến số nghiên cứu. Thời gian từ khi có kết quả xét nghiệm đến khi quản lý điều trị: được tính bằng ngày, được xác định theo tứ phân vị và lấy mốc điểm tứ phẩn vị thứ nhất (điểm cắt $25,0 \%$ ). Tuân thủ kết quả xét nghiệm được xác định là khi bệnh nhân thực hiện từ $70,0 \%$ số xét nghiệm theo quy định. Kết quả điêu trị: được xác định gồm điêu trị thành công (khỏi, hoàn thành điều trị) và điêuu trị không thành công (tử vong, thất bại, bỏ trị và chuyển).

2.6. Phương pháp xử lý số liệu: bằng phần mềm SPSS 22.0

2.7. Đạo đức nghiên cứu: nghiên cứu được thông qua Hội đồng đạo đức của trường Đại học
Y Dược - Đại học Thái Nguyên theo Quyết định số 1672 ngày 17/9/2020.

\section{KẾT QUẢ NGHIÊN CỨU}

Bảng 1. Đặc điểm chung của bệnh nhân lao kháng Rifampicin

\begin{tabular}{|c|c|c|c|}
\hline \multicolumn{2}{|c|}{ Đắc điếm } & SL & \% \\
\hline \multirow{4}{*}{ Tuổi } & $<15$ & 1 & 1,1 \\
\cline { 2 - 4 } & $15-29$ & 16 & 17,4 \\
\cline { 2 - 4 } & $30-44$ & 38 & 41,3 \\
\cline { 2 - 4 } & $45-59$ & 33 & 35,9 \\
\cline { 2 - 4 } & $\geq 60$ & 4 & 4,3 \\
\cline { 2 - 4 } & Trung bình & $40,9 \pm 12,3$ \\
\hline \multirow{2}{*}{ Giới } & Nam & 73 & 79,3 \\
\cline { 2 - 4 } & Nữ & 19 & 20,7 \\
\hline \multirow{2}{*}{$\begin{array}{c}\text { Nghề } \\
\text { nghiệp }\end{array}$} & Nông dân & 66 & 71,7 \\
\cline { 2 - 4 } & $\begin{array}{c}\text { Khác (công nhân, } \\
\text { Kưuu trí...) }\end{array}$ & 26 & 28,3 \\
\hline \multirow{2}{*}{$\begin{array}{c}\text { Kinh tế hộ } \\
\text { gia đình }\end{array}$} & Nghèo, cận nghèo & 28 & 30,4 \\
\cline { 2 - 4 } Nơi cư trú & Không nghèo & 64 & 69,6 \\
\cline { 2 - 4 } & Nông thôn & 62 & 67,4 \\
\hline \multirow{3}{*}{ Khác (thành thị...) } & 30 & 32,6 \\
\hline \multicolumn{2}{|c|}{ Tống } & $\mathbf{9 2}$ & $\mathbf{1 0 0 , 0}$ \\
\hline
\end{tabular}

Bệnh nhân RR-TB chủ yếu ở lứa tuối từ 30-44 chiếm tỉ lệ $41,3 \%$, tỉ lệ bệnh nhân <15 tuổi $1,1 \%$ và $\geq 60$ tuổi $4,3 \%$. Tí lệ bệnh nhân nam $79,3 \%$, tỉ lệ bệnh nhân có nghề nghiệp là nông dân $71,7 \%$, kinh tế nghèo, cận nghèo chiếm $30,4 \%$ và nơi sống chủ yếu ở nông thôn $67,4 \%$.

Bảng 2. Đặc điểm về tiền sử lao, bệnh kèm theo và HIV của bệnh nhân lao kháng Rifampicin

\begin{tabular}{|c|c|c|c|}
\hline \multicolumn{2}{|c|}{ Chỉ số } & SL & $\mathbf{0}$ \\
\hline \multirow{2}{*}{$\begin{array}{c}\text { Tiền sử } \\
\text { lao }\end{array}$} & Lao mới & 24 & 26,1 \\
\cline { 2 - 4 } & Lao điều trị lại & 68 & 73,9 \\
\hline \multirow{2}{*}{$\begin{array}{c}\text { Bệnh kèm } \\
\text { theo }\end{array}$} & Có (viêm gan...) & 23 & 25,0 \\
\cline { 2 - 4 } & Không & 69 & 75,0 \\
\hline \multirow{2}{*}{ HIV } & HIV(-) & 74 & 80,4 \\
\cline { 2 - 4 } & $\operatorname{HIV}(+)$ & 18 & 19,6 \\
\hline \multicolumn{2}{|c|}{ Tống } & $\mathbf{9 2}$ & $\mathbf{1 0 0 , 0}$ \\
\hline
\end{tabular}

Tỉ lệ bệnh nhân RR-TB có tiền sử điều trị lao là $73,9 \%$, lao mới là $26,1 \%$. Tỉ lệ bệnh nhân RRTB có bệnh kèm theo là $25,0 \%$ và có $H I V(+)$ là $19,6 \%$.

Bảng 3. Đặc điểm chẩn đoán và chế độ đîều trị của bệnh nhân lao kháng Rífampicin

\begin{tabular}{|c|c|c|c|}
\hline \multicolumn{2}{|c|}{ Chỉ số } & SL & \% \\
\hline $\begin{array}{c}\text { Phương pháp } \\
\text { chẩn đoán }\end{array}$ & GenXpert & 92 & 100 \\
\hline $\begin{array}{c}\text { Vị trí tốn } \\
\text { thương }\end{array}$ & Phối & 90 & 97,8 \\
\cline { 2 - 4 } & Ngoài phối & 2 & 2,2 \\
\hline $\begin{array}{c}\text { Thế lao qua } \\
\text { soi đờm }\end{array}$ & AFB(+) & 67 & 72,8 \\
\cline { 2 - 4 } & AFB(-) & 25 & 27,2 \\
\hline $\begin{array}{c}\text { Thời gian từ } \\
\text { khi có kết quả }\end{array}$ & $\leq 4$ ngày & 33 & 35,9 \\
\cline { 2 - 4 } & $>4$ ngày & 59 & 64,1 \\
\hline
\end{tabular}




\begin{tabular}{|c|c|c|c|}
\hline $\begin{array}{c}\text { XN tới khi } \\
\text { được điêuu trị }\end{array}$ & & \\
\hline $\begin{array}{c}\text { Chế độ điều } \\
\text { trị }\end{array}$ & 9 tháng & 37 & 40,2 \\
\cline { 2 - 4 } Tống & 20 tháng & 55 & 59,8 \\
\hline \multicolumn{2}{|c|}{ Tóng } & $\mathbf{9 2}$ & $\mathbf{1 0 0 , 0}$ \\
\hline
\end{tabular}

Toàn bô $(100,0 \%)$ bênh nhân RR-TB được chẩn đoán bằng GenXpert. Tỉ lệ bênh nhân lao phổi là 97,8\%; thể $\mathrm{AFB}(+)$ là $72,8 \%$; được chỉ định điều trị 20 tháng 59,8\%, 9 tháng 40,2\%.

Bảng 4. Kết quá theo dối điêuu trị bênh nhân lao kháng Rifampicin

\begin{tabular}{|c|c|c|c|}
\hline \multicolumn{2}{|c|}{ Theo dõi điêuu trị } & SL & $\%$ \\
\hline Nơi quản lý ở & TYT xã phường & 79 & 85,9 \\
giai đoạn duy trì & Y tế trại giam & 13 & 14,1 \\
\hline Tư vấn trước điều trị & 92 & 100,0 \\
\hline Đo thính lực & 92 & 100,0 \\
\hline \multicolumn{2}{|c|}{ Soi đáy mắt } & 92 & 100,0 \\
\hline \multicolumn{2}{|c|}{ Xét nghiệm công thức máu } & 92 & 100,0 \\
\hline Xét nghiệm chức năng gan & 92 & 100,0 \\
\hline Tuân thủ XN đạt & 26 & 28,3 \\
\hline
\end{tabular}

Toàn bộ $(100,0 \%)$ bênh nhân RR-TB được thực hiện đủ các bước trước điều trị theo quy định. Tỉ lệ bệnh nhân tuân thủ xét nghiệm trong quá trình theo dõi điều tri là $28,3 \%$.

Bảng 5. Kết quả đî̀u trị của bệnh nhân lao kháng Rifampicin $(n=86) *$

\begin{tabular}{|c|c|c|c|}
\hline \multicolumn{2}{|c|}{ Kết quả điêu trị } & $\mathbf{S L}$ & $\mathbf{\%}$ \\
\hline \multirow{2}{*}{$\begin{array}{c}\text { Điều trị } \\
\text { thành công }\end{array}$} & Khỏi & 3 & 3,5 \\
\cline { 2 - 4 } & $\begin{array}{c}\text { Hoàn thành } \\
\text { điều trị }\end{array}$ & 65 & 75,5 \\
\hline \multirow{2}{*}{$\begin{array}{c}\text { Điều trị } \\
\text { không thành } \\
\text { công }\end{array}$} & Tử vong & 9 & 10,5 \\
\cline { 2 - 4 } & Thất bại & 2 & 2,3 \\
\cline { 2 - 4 } & Bỏ trị & 6 & 7,0 \\
\cline { 2 - 4 } & Chuyển & 1 & 1,2 \\
\hline \multicolumn{2}{|c|}{ Tổng } & $\mathbf{8 6}$ & $\mathbf{1 0 0 , 0}$ \\
\hline
\end{tabular}

Có 68 bệnh nhân điều trị thành công: khỏi 3,5\%; hoàn thành điều trị 75,6\%; điều trị không thành công: tử vong $10,5 \%$, thất bại $2,3 \%$, bỏ trị $7,0 \%$, chuyển $1,2 \%$.

Bảng 6. Liên quan giữa các yếu tố nhân khẩu học, tiền sử với kêt quả điều trị (n=86)

\begin{tabular}{|c|c|c|c|c|c|c|}
\hline \multirow{2}{*}{\multicolumn{2}{|c|}{ Chỉ số $\quad$ Kết quả điều trị }} & \multicolumn{2}{|c|}{ Không thành công } & \multicolumn{2}{|c|}{ Điêu trị thành công } & \multirow[b]{2}{*}{$\mathbf{p}$} \\
\hline & & SL & $\%$ & SL & $\%$ & \\
\hline \multirow{2}{*}{ Tuổi } & $<45$ & 12 & 23,1 & 40 & 76,9 & \multirow{2}{*}{$>0,05$} \\
\hline & $\geq 45$ & 6 & 17,6 & 28 & 82,4 & \\
\hline \multirow{2}{*}{ Giới } & Nam & 17 & 25,0 & 51 & 75,0 & \multirow[b]{2}{*}{$>0,05$} \\
\hline & Nữ & 1 & 5,6 & 17 & 94,4 & \\
\hline \multirow[b]{2}{*}{ Nghề nghiệp } & Nông dân & 10 & 16,7 & 50 & 83,3 & \multirow{2}{*}{$>0,05$} \\
\hline & Khác (công nhân...) & 8 & 30,8 & 18 & 69,2 & \\
\hline \multirow{2}{*}{$\begin{array}{c}\text { Kinh tế hộ gia } \\
\text { đînh }\end{array}$} & Nghèo, cận nghèo & 11 & 40,7 & 16 & 59,3 & \multirow{2}{*}{$<0,05$} \\
\hline & Đủ ăn & 7 & 11,9 & 52 & 88,1 & \\
\hline \multirow{2}{*}{$\begin{array}{c}\text { Tiền sử điều } \\
\text { trị }\end{array}$} & Lao điều trị lại & 0 & 0,0 & 24 & 100,0 & \multirow{3}{*}{$<0,05$} \\
\hline & Lao mới & 18 & 29,0 & 44 & 71,0 & \\
\hline & Tống & 18 & 20,9 & 68 & 79,1 & \\
\hline
\end{tabular}

Có mối liên quan có ý nghĩa thống kê giữa tình trạng kinh tế, tiền sử lao với kết quả điều trị lao kháng Rifampicin $(p<0,05)$.

Bảng 7. Liên quan giữa các đặc điểm bệnh với kêt quả điều trị $(n=86)$

\begin{tabular}{|c|c|c|c|c|c|c|}
\hline \multirow{2}{*}{ Chỉ số } & \multirow[t]{2}{*}{ Kết quả điều trị } & \multicolumn{2}{|c|}{ Không thành công } & \multicolumn{2}{|c|}{ Điêu trị thành công } & \multirow[b]{2}{*}{$\mathbf{p}$} \\
\hline & & $\mathbf{S L}$ & $\%$ & $\mathbf{S L}$ & $\%$ & \\
\hline \multirow{2}{*}{ Bệnh kèm theo } & Có & 10 & 45,5 & 12 & 54,5 & \multirow[b]{2}{*}{$<0,01$} \\
\hline & Không & 8 & 12,5 & 56 & 87,5 & \\
\hline \multirow{2}{*}{ Tình trạng HIV } & $\mathrm{HIV}(+)$ & 9 & 52,9 & 8 & 47,1 & \multirow{2}{*}{$<0,001$} \\
\hline & HIV(-) & 9 & 13,0 & 60 & 87,0 & \\
\hline \multirow{2}{*}{$\begin{array}{c}\text { Thế lao qua soi } \\
\text { đờm }\end{array}$} & $\mathrm{AFB}(+)$ & 17 & 27,9 & 44 & 72,1 & \multirow{2}{*}{$<0,05$} \\
\hline & $\mathrm{AFB}(-)$ & 1 & 4,0 & 24 & 96,0 & \\
\hline \multirow{2}{*}{ Vị trí tổn thương } & Phô̂i & 18 & 21,2 & 67 & 78,8 & \multirow{2}{*}{$>0,05$} \\
\hline & Ngoài phối & 0 & 0 & 1 & 100 & \\
\hline \multirow{2}{*}{$\begin{array}{c}\text { Thời gian chờ } \\
\text { điều trị }\end{array}$} & $\leq 4$ ngày & 3 & 10,3 & 26 & 89,7 & \multirow{2}{*}{$>0,05$} \\
\hline & $>4$ ngày & 15 & 26,3 & 42 & 73,7 & \\
\hline \multirow{2}{*}{ Chế độ điều trị } & 20 tháng & 16 & 29,6 & 38 & 70,4 & \multirow{2}{*}{$<0,05$} \\
\hline & 9 tháng & 2 & 6,3 & 30 & 93,7 & \\
\hline \multirow{2}{*}{$\begin{array}{l}\text { Nơi quản lý GĐ } \\
\text { duy trì }\end{array}$} & Trại giam & 8 & 61,5 & 5 & 38,5 & \multirow{2}{*}{$<0,001$} \\
\hline & TYT xã phường & 10 & 13,7 & 63 & 86,3 & \\
\hline \multirow{2}{*}{$\begin{array}{c}\text { Tuân thủ xét } \\
\text { nghiệm }\end{array}$} & Không đạt & 17 & 28,3 & 43 & 71,7 & \multirow{2}{*}{$<0,05$} \\
\hline & Đat & 1 & 3,8 & 25 & 96,2 & \\
\hline
\end{tabular}




\begin{tabular}{|c|c|c|c|c|c|c|}
\hline \multirow{2}{*}{$\begin{array}{c}\text { Tác dụng không } \\
\text { mong muốn }\end{array}$} & Có & 7 & 50,0 & 7 & 50,0 & \multirow{2}{*}{$<0,05$} \\
\hline & Không & 11 & 15,3 & 61 & 84,7 & \\
\hline \multicolumn{2}{|c|}{ Tống } & 18 & 20,9 & 68 & 79,1 & \\
\hline
\end{tabular}

Có mối liên quan có ý nghĩa thống kê giữa bệnh kèm theo, tình trạng HIV, thế lao qua soi đờm, chế độ điều trị, nơi quản lý bệnh nhân giai đoạn duy trì, tuân thủ xét nghiệm và tác dụng không mong muốn với kết quả điều trị lao kháng Rifampicin $(p<0,05)$.

\section{BÀN LUÂN}

Trước thực tế RR-TB đang có chiêu hướng diễn biến phức tạp tại Việt Nam, gây ảnh hưởng không nhỏ tới mục tiêu thanh toán bệnh lao của CTCLQG. Việc quản lý điều trị bệnh nhân RR-TB cần có những nỗ lực thực sự nhẳm đáp ứng yêu cầu đó. Nghiên cứu của chúng tôi là nghiên cứu đầu tiên về kết quả quản lý điêu trị RR-TB ở Thái Nguyên trong giai đoạn 2016-2020. Nghiên cứu này sẽ cung cấp các bằng chứng khoa học và đưa ra các đề xuất nhằm nâng cao chất lượng quản lý điều trị RR-TB trong giai đoạn tới.

Nghiên cứu của chúng tôi cho thấy tỉ lệ bệnh nhân < 15 tuổi là $1,1 \%$ và $\geq 60$ là $4,3 \%$; tương đương với nghiên cứu của Van Le Hong và cs (2020): < 18 tuổi là $1,4 \%$ và > 60 tuổi là $8,7 \%$ [6]. Đây là một điểm cần lưu ý trong CTCLQG do ở nhóm đối tượng này có những đặc thù khác trong đáp ứng quản lý điều trị RR-TB. Tỉ lệ bệnh nhân nghiên cứu có nghề nghiệp là nông dân $71,7 \%$; kinh tế hộ gia đình nghèo, cận nghèo chiếm $30,4 \%$ và nơi cư trú chủ yếu ở vùng nông thôn $67,4 \%$. Các kết quả này phù hợp với đặc điểm xã hội thường gặp của bệnh nhân lao tại Việt Nam.

Tỉ lệ bệnh nhân RR-TB có tiền sử điều trị lao là $73,9 \%$, lao mới là $26,1 \%$ và có $H I V(+)$ là $19,6 \%$. Kết quả này của chúng tôi có sự khác biệt với nghiên cứu của Phuong N.T.M. và cs (2016) [5] và Van Le Hong và cs (2020) với tỉ lệ lao mới lần lượt là $2,0 \%$ và $5,6 \%$ và $\mathrm{HIV}(+)$ lần lượt là 4,0\% và $9,6 \%$ [5], [6]. Đây là sự khác biểt về địa điểm nghiên cứu và đối tượng nghiên cứu. Nghiên cứu cũng thấy toàn bộ $(100,0 \%)$ bệnh nhân RR-TB được chẩn đoán bằng GeneXpert. Đây là điểm phù hợp với thực nghiên cứu tiến hành tại Thái Nguyên, nơi chưa được cung cấp các thiết bi chẩn đoán RR-TB khác ngoài GeneXpert. Tỉ lệ bệnh nhân lao phổi là $97,8 \%$; thể $A F B(+)$ là $72,8 \%$. Như vậy, phân lớn bệnh nhân lao kháng thuốc là lao phổi và có $\mathrm{AFB}(+)$, tương đồng với nghiên cứu của Phuong N.T.M. và cS (2016) cho thể lao phổi chiếm $99,0 \%$, và $A F B(+)$ là $85,0 \%[5]$.

Một điểm cần lưu ý trong trong quản lý điều trị lao là thời gian từ khi có kết quả xét nghiệm chẩn đoán RR-TB đến khi được quản lý điêu trị.
Thời gian này càng kéo dài là yếu tố làm tăng nguy cơ lây bệnh ra cộng đồng. Kết quả nghiên cứu của chúng tôi thẩy thời gian từ khi có kết quả xét nghiệm đến khi quản lý điều trị: $\leq 4$ ngày là $35,9 \%,>4$ ngày là $64,1 \%$. Thời gian này của chúng tôi thấp hơn kết quả của Bulabula A.N.H. và CS (2019) thời gian trung vị là 12 ngày (thấp nhất là 3 ngày, cao nhất 62,4 ngày) [3]. Theo Bulabula A.N.H. và $C S$, việc kéo dài là do hết thuốc, bệnh nhân RR-TB phải chuyển sang tỉnh khác để quản lý điều trị. Điều này khác so với Thái Nguyên, không để tình trạng thiếu thuốc. Thực tế, có những bệnh nhẩn không muốn điều trị, có những bệnh nhân sau khi biết kết quả xét nghiệm lại muốn đi kiểm tra lại ở bệnh viện tuyến trung ương hoặc có những bệnh nhân cần sắp xếp công việc trước khi điêu trị lên đã làm cho thời gian đi quản lý điều trị kéo dài. Măc dù thời gian đi quản lý điều trị của bênh nhân còn bất cập nhưng việc thực hiện các hoạt động khác trong quản lý điều trị của bệnh nhẩn lao lại rất tốt. Toàn bộ $(100,0 \%)$ bệnh nhân RRTB được thực hiện đủ các bước trước điều trị theo quy định như tư vấn điều trị, làm các xét nghiệm theo dõi trước điều trị như đo thính lực, soi đáy mắt, xét nghiệm máu, xét nghiệm chức năng gan... theo quy định của Bộ Y tế [2].

Nghiên cứu cho tî lệ RR-TB được chỉ định điêu trị 20 tháng 59,8\% và 9 tháng 40,2\%. Kết quả này của chúng tôi có sự khác biệt với Bulabula A.N.H. và cs (2019) với các phác đồ 9 tháng $21,0 \%, 20$ tháng $34,0 \%$ và 24 tháng $40,0 \%$ [3]. Sự khác biệt này là do đặc điểm mẫu nghiên cứu. Kết quả điều trị của bệnh nhân RRTB trong nghiên cứu này là thành công $79,0 \%$ (khỏi 3,5\%; hoàn thành điêu trị $75,5 \%$ ), tử vong $10,5 \%$, thất bại $2,3 \%$, bỏ trị $7,0 \%$, chuyển $1,2 \%$. Kết quả của chúng tôi cao hớn so với nghiên cứu của Katende $B$. và cs $(2020)$ cho tỉ lệ thành công $69,8 \%$, tử vong $28,8 \%$, thất bại $0,4 \%$ và chuyển $1,0 \%[4]$. Tî lệ tử vong trong nghiên cứu của chúng tôi chiếm $10,5 \%$ đều gặp ở các bệnh nhân có $\mathrm{HIV}(+)$ và cao tuổi.

Kinh tế hộ gia đình nghèo, cận nghèo và có tiền sử điều trị lao đều liên quan với kết quả điều trị RR-TB không thành công $(p<0,05)$. So sánh với nghiên cứu của Van Le Hong và cs (2020) thấy bệnh nhân có tiền sử điều trị lao có nguy cơ 
điều trị thất bại cao gấp 5,53 lần (95\%CI:2,85$19,72)[6]$. Thực tế kinh tế khó khăn, thu nhập bi mất trong quá trình điều trị lao kéo dài và việc nhờn thuốc do đã từng điều trị lao trước đó ảnh hưởng đến quá trình điêu trị lao.

Các nghiên cứu trước cho thấy có mối liên quan giứa $\operatorname{HIV}(+), A F B(+)$ [4], [6], tác dụng không mong muốn nặng của thuốc [3] có liên quan đến kết quả điều trị RR-TB. Bênh nhân có bệnh đồng mắc, $\operatorname{HIV}(+)$ thì kết quả điều trị không thành công sẽ cao hơn, điều này hoàn toàn phù hợp với y văn. Thực tế, nếu phải điều trị kéo dài, gây tốn kém, mất thời gian, mêtt mỏi và bi ảnh hưởng của thuốc thì sẽ ảnh hưởng đến tâm lý của bệnh nhân, làm cho bệnh nhân có xu hướng bỏ trị hoặc không tuân thủ điều trị, qua đó ảnh hưởng kết quả điều trị. Nghiên cứu của chúng tôi phù hợp với y văn và phù hợp với các nghiên cứu trước khi cho kết quả: có mối liên quan có ý nghĩa thống kê giữa mắc bệnh kèm theo, $\operatorname{HIV}(+)$, $\mathrm{AFB}(+)$, chế độ điều trị 20 tháng, bệnh nhân tại trại giam, không tuân thủ xét nghiệm và gặp tác dụng không mong muốn với kết quả điều trị RRTB không thành công $(p<0,05)$.

\section{KẾT LUẬN}

Tuổi trung bình của bệnh nhân RR-TB là $40,9 \pm 12,3$, tỉ lệ nam $79,3 \%$. Tỉ lệ có tiền sử điều trị lao $73,9 \%$, lao mới $26,1 \%$ và $\operatorname{HIV}(+) 19,6 \%$. Tỉ lệ lao tại phổi 97,8\%; thể AFB(+) 72,8\%. Tỉ lệ tuân thủ xét nghiệm trong quá trình theo dõi điều trị $28,3 \%$. Tỉ lệ điêuu trị khỏi $3,5 \%$, hoàn thành điều trị $75,5 \%$, tử vong $10,5 \%$, thất bại $2,3 \%$, bỏ trị $7,0 \%$, chuyển $1,2 \%$. Có mối liên quan giữa tình trạng kinh tế hộ gia đình nghèo, tiên sử lao, mắc bệnh kèm theo, $\operatorname{HIV}(+)$, $\mathrm{AFB}(+)$, thời gian điều trị 20 tháng, bệnh nhân tại trại giam, không tuân thủ xét nghiệm và gặp tác dụng không mong muốn với kết quả điều trị RR-TB không thành công $(p<0,05)$.

\section{TÀI LIÊU THAM KHẢO}

1. Chương trình chống lao quốc gia (2021), Báo cáo tổng kết chương trình chống lao năm 2020, Bộ Y tế, Hà Nội.

2. Bô Y tế (2020), Câp nhât hướng dẫn chẩn đoán điều trị và dự phòng bệnh lao, Nhà xuất bản $Y$ học, Hà Nội.

3. Bulabula A.N.H., Nelson J.A., Musafiri E.M., et al. (2019), "Prevalence, Predictors, and Successful Treatment Outcomes of Xpert MTB/RIFidentified Rifampicin-resistant Tuberculosis in Postconflict Eastern Democratic Republic of the Congo 2012-2017: A Retrospective Province-Wide Cohort Study", Clinical infectious diseases: an official publication of the Infectious Diseases Society of America, 69 (8), pp. 1278-1287.

4. Katende B., Esterhuizen T.M., Dippenaar A., et al. (2020), "Rifampicin Resistant Tuberculosis in Lesotho: Diagnosis, Treatment Initiation and Outcomes", Sci Rep, 10 (1), pp. 1917.

5. Phuong N.T.M., Nhung N.V., Hoa N.B., et al. (2016), "Management and treatment outcomes of patients enrolled in MDR-TB treatment in Viet Nam", Public health action, 6 (1), pp. 25-31.

6. Van Le Hong, Phu Phan Trieu, Vinh Dao Nguyen, et al. (2020), "Risk factors for poor treatment outcomes of 2266 multidrug-resistant tuberculosis cases in Ho Chi Minh City: a retrospective study", BMC Infectious Diseases, 20 (1), pp. 164

7. World Health Organization (2020), Global tuberculosis report 2020, World Health Organization, Geneva, Switzerland.

\section{ĐĂC ĐIỂM TỔN THƯƠNG VÕNG MAC TRÊN BỆNH NHÂN ĐÁI THÁO ĐƯỜNG TẠI BỆNH VIỆN ĐA KHOA KHU VỰC PHÚC YÊN}

\section{TÓM TẮT}

Mục tiêu: 1, Mô tả đặc điểm lâm sàng của tổn thương võng mạc trên bệnh nhân bị bệnh đái tháo đường (ĐTĐ) tại Bệnh viện đa khoa khu vực Phúc Yên. 2, Nhận xét một số yếu tố liên quan đến bệnh võng mạc đái tháo đường trên nhóm bệnh nhân

${ }^{1}$ Bệnh viên Măt trung ương

2Bêenh viện đa khoa Phúc Yên

Chịu trách nhiệm chính: Vũ Tuấn Anh

Email: vta.oph@gmail.com

Ngày nhận bài: 3.3.2021

Ngày phản biên khoa hoc: 26.4.2021

Ngày duyệt bài: 7.5.2021

\section{Vũ Tuấn Anh', Nguyễn Thị Ngọc Hân²} nghiên cứu. Đối tượng và phương pháp nghiên cứu: nghiên cưú mô tả cắt ngang trên 273 bệnh nhân ĐTÐ (546 mắt), thu thập các thông tin cơ bản (tuổi, giới, thời gian mắt ĐTĐ, typ ĐTÐ...), khám đáy mắt và chup mach huỳnh quang xác đinh tổn thương và giai đoạn bệnh võng mạc ĐTÐ. Kết quả: tuổi bệnh nhân trung bình $61,6 \pm 11,8$ (17-89); thi lức giảm vừa chiếm chủ yếu $50 \%$ (273/546); tỷ lệ mắc bệnh võng mac ĐTÐ chiếm 25,5\% (139/546 mắt), trong đó giai đoạn chưa tăng sinh nhẹ là $21,2 \%$ (113 mắt), chưa tăng sinh vừa $0,9 \%$ (5 mắt), chưa tăng sinh nặng $0,7 \%$ (4 mắt) và tăng sinh $2,7 \%$ (15 mắt), tỷ lẹ phù hoàng điểm $6 \%$ (33 mắt); có mối liên quan chặt chẽ giữa bệnh võng mạc ĐTÐ với thời gian mắc bênh ĐTÐ $(p<0,001)$, với kiểm soát tốt đường máu $(\mathrm{H} \dot{\mathrm{b} A} 1 \mathrm{c}<7)$ 